\title{
Comparison of incision size and intraocular lens performance after implantation with three preloaded systems and one manual delivery system
}

This article was published in the following Dove Press journal:

Clinical Ophthalmology

\author{
Javier Mendicute' \\ Thierry Amzallag² \\ Lixin Wang ${ }^{3}$ \\ Aldo A Martinez ${ }^{4}$ \\ 'Department of Ophthalmology, \\ Hospital Universitario Donostia, \\ San Sebastián, Spain; ${ }^{2}$ Department \\ of Ophthalmology, Ophthalmic \\ Institute, North of France, \\ Somain, France; ${ }^{3}$ Ophthalmology \\ Unit, Novartis Pharmaceuticals \\ Corporation, Fort Worth, TX, USA; \\ ${ }^{4}$ Medical Affairs, Alcon Laboratories, \\ Inc., Fort Worth, TX, USA
}

Purpose: To compare corneal incision size and intraocular lens (IOL) performance/behavior following implantation with the following delivery systems: system $U$ (UltraSert ${ }^{\circledR}$ ), system $S$ (Hoya iSert $^{\circledR}$ 250/251), system T (Tecnis ${ }^{\circledR}$ iTec), and a manual system (Monarch ${ }^{\circledR}$ III Delivery System).

Setting: Six study sites (four in Spain and two in France).

Design: Prospective, multicenter, parallel-group, randomized, subject-masked, postmarket clinical study.

Materials and methods: Subjects were enrolled based on predetermined inclusion/exclusion criteria. The effectiveness end points compared corneal incision size and enlargement after IOL implantation (day of surgery) among all delivery systems. Exploratory end points included mean enlargement of corneal incision size, rates of trapped trailing haptic, IOL adherence to the plunger tip, nozzle tip splitting, and mean surgically induced astigmatism (SIA) at postoperative visit. Results: One hundred and nine subjects participated in the study. The mean corneal incision size following IOL implantation was $2.35 \pm 0.019 \mathrm{~mm}$ for system $\mathrm{U}, 2.47 \pm 0.016 \mathrm{~mm}$ for system $\mathrm{T}, 2.54 \pm 0.019 \mathrm{~mm}$ for system $\mathrm{S}$, and $2.49 \pm 0.011 \mathrm{~mm}$ for the manual system. There were five instances of trapped trailing haptic (all system $\mathrm{T}$ group, $\mathrm{N}=26$ ), one instance of IOL adherence to the plunger tip (system $\mathrm{S}$ group, $\mathrm{N}=26$ ), and six instances of nozzle tip splitting (all system $\mathrm{S}$ group, $\mathrm{N}=26$ ). System $\mathrm{U}$ had the least SIA (postoperative Day 1) (SIA Centroid $=0.10$ diopters [axis: $\left.83.06^{\circ}\right]$ ).

Conclusion: Preloaded delivery system U supported the completion of surgery with the smallest incision size, the least SIA (postoperative Day 1), and no trapped trailing haptics or nozzle tip splitting compared to two other preloaded systems and one manual system.

Keywords: corneal incision, intraocular lens, preloaded IOL injector, UltraSert

\section{Plain language summary}

During cataract surgery, the surgeon creates an incision in the cornea to remove the cataract lens and implant an intraocular lens (IOL). Reduced incision size is associated with decreased inflammation after surgery, quicker wound healing, and quicker recovery of vision. Traditionally, IOL injector systems required that IOLs be manually loaded into the device. More recently, devices with IOLs preloaded into an injector have been created to enhance the consistency and efficiency of the cataract surgery procedure. This study compared the performance of three preloaded $\left(\right.$ UltraSert $^{\circledR}$, system U; Tecnis ${ }^{\circledR}$ iTec, system T; and Hoya iSert ${ }^{\circledR}$ 250/51, system S) and one manually loaded injector system (Monarch ${ }^{\circledR}$ III Delivery System). Measurements included size of the corneal incision before and after IOL implantation and rates of various complications during IOL delivery. The study enrolled 109 subjects. After IOL implantation, mean corneal incision size was smallest after the use of system U. System U was not associated
Correspondence: Javier Mendicute Department of Ophthalmology, Hospital Universitario Donostia, Paseo Dr Beguiristáin, II5, 20014 San Sebastián, Spain

Tel +34943322233

Email mendicutejavier@gmail.com

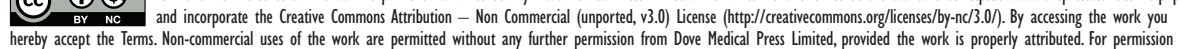
for commercial use of this work, please see paragraphs 4.2 and 5 of our Terms (https://www.dovepress.com/terms.php). 
with any complications during IOL delivery. For system T, there were instances when one of the curved arms of the IOL got stuck in the injector nozzle during delivery. For system $\mathrm{S}$, there were cases of the IOL getting stuck to the plunger and of nozzle tip splitting. In conclusion, preloaded system $U$ resulted in the smallest incision size after IOL implantation and was not associated with any complications during IOL delivery.

\section{Introduction}

Modern cataract surgery is typically highly successful, but depends on optimal surgical technique to minimize the risk of complications. ${ }^{1-4}$ Advancements in preloaded injectable intraocular lens (IOL) delivery systems can help reduce procedural variability during cataract surgery by avoiding IOL injector loading error and reducing potential IOL damage, surgical complexity, and operative time. ${ }^{5}$ Increasingly, precise preloaded IOL systems also enable incision size and enlargement to be significantly reduced during surgery, which helps to reduce postoperative inflammation, minimize surgically induced astigmatism (SIA), and allow for more rapid visual and wound rehabilitation while reducing the chance of contamination during IOL implantation. ${ }^{6-8}$

The UltraSert ${ }^{\circledR}$ preloaded delivery system (preloaded system U; Alcon Laboratories, Inc., Fort Worth, TX, USA) is US Food and Drug Administration (FDA)-approved for use with the AcrySof ${ }^{\circledR}$ IQ Aspheric IOL (IOL IQ; Alcon Laboratories, Inc.) in patients undergoing cataract surgery and is a single-use system made up of a nozzle, main body, and plunger that delivers the preloaded IOL by manually advancing the plunger with a push mechanism (Figure 1). Unlike other delivery systems, preloaded system $U$ has a depth guard that is intended to help surgeons control insertion depth, provide a counterforce during insertion, minimize the

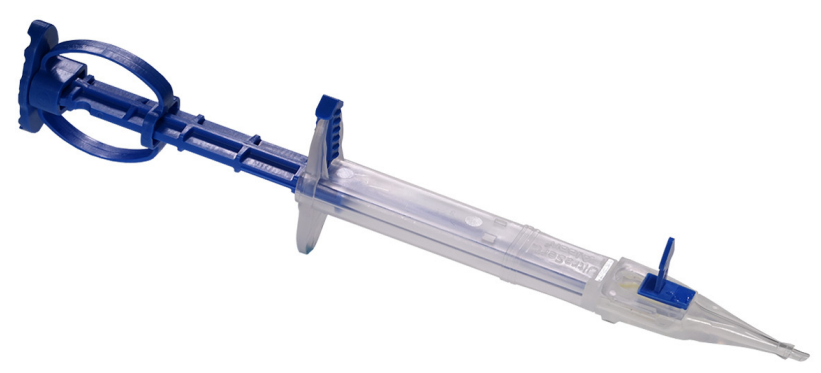

Figure I The UltraSert ${ }^{\circledR}$ preloaded delivery system.

Notes: The UltraSert preloaded delivery system (Alcon Laboratories, Inc., Fort Worth, TX, USA) is a single-use system made up of a nozzle, main body, and plunger that delivers the preloaded IOL by manually advancing the plunger with a push mechanism. The system is Food and Drug Administration (FDA)-approved for use with the AcrySof ${ }^{\circledR}$ IQ Aspheric IOL (Alcon Laboratories, Inc.) in patients undergoing cataract surgery.

Abbreviation: IOL, intraocular lens. stretch of the incision, and preserve incision architecture. An ex vivo preclinical study in porcine eyes that evaluated the corneal incision size after IOL implantation showed that preloaded system $U$ had the smallest final corneal incision size compared to two other preloaded delivery systems (preloaded system S: Hoya iSert ${ }^{\circledR} 250 / 251$; Hoya Surgical Optics, Inc., Singapore; preloaded system T: Tecnis ${ }^{\circledR}$ iTec; Abbott Medical Optics Inc, Santa Ana, CA, USA), making it a compelling candidate for clinical use. ${ }^{9}$

In the present study, corneal incision size and IOL performance (trapped trailing haptic, IOL adhesion, cartridge damage during and after implantation) were evaluated in patients undergoing cataract surgery with one of the four IOL delivery systems: preloaded delivery system U (UltraSert) with IOL IQ, preloaded delivery system $\mathrm{T}$ with IOL $\mathrm{T}$ (Tecnis iTec), preloaded delivery system $\mathrm{S}$ with IOL H (Hoya iSert 250/51), and a manual delivery system (Monarch ${ }^{\circledR}$ III Delivery System with Monarch $^{\circledR}$ III D cartridge and IOL IQ).

\section{Materials and methods Study design}

This was a prospective, multicenter, parallel-group, randomized, subject-masked, postmarket clinical study (registered with the US National Institutes of Health as NCT02826421) comparing corneal incision size after IOL implantation with the use of one of the four delivery systems. The study was conducted by six investigators from six sites (four in Spain and two in France).

The study was conducted in accordance with the principles of the Declaration of Helsinki, Good Clinical Practice, and the Code of Federal Regulations. The Clinical Research Ethics Committee of Euskadi reviewed and approved the protocol on behalf of the four study sites in Spain. The SouthMediterranean II Ethics Committee reviewed and approved the protocol on behalf of the two study sites in France. The institutional review board or ethics committee at each study site approved the study protocol. Written informed consent was obtained from all subjects before enrollment.

Study participants included adults aged 22 years or older with good general and ocular health who had a cataract in at least one eye with preoperative astigmatism of $<1.0$ diopters (D). Patients with any of the following conditions were excluded from the study: systemic disease that affects the cornea, inflammation or edema of the cornea, previous or planned refractive or corneal surgery during the subject's participation in the study, previous corneal transplant, previous retinal detachment, pregnancy or lactation, current 
participation in another investigational drug or device study, or any condition observed before or during surgery that may affect the success of the cataract surgery. Subjects were screened, enrolled, and randomly assigned to preloaded system $U$, preloaded system $T$, preloaded system $S$, or the manual delivery system.

First incision and cataract extraction were performed according to each site's standard practice except for procedures described below. For the initial incision, a paracentesis incision up to $1.2 \mathrm{~mm}$ in width was made near the limbus. Viscoat $^{\circledR}$ ophthalmic viscosurgical device (OVD) (Alcon Laboratories, Inc.) was injected into the anterior chamber, and a second paracentesis incision of the same size could be made at the discretion of the investigator. IOLs were delivered according to the manufacturer's instructions that were provided with each individual delivery system. For preloaded system $\mathrm{U}$, preloaded system $\mathrm{T}$, and preloaded system S, IOLs were delivered through a straight temporal clear corneal incision of $2.2 \mathrm{~mm}$. For the manual delivery system, IOLs were delivered through a straight temporal clear corneal incision of $2.4 \mathrm{~mm}$. The clear corneal incision was made using the dual bevel ClearCut ${ }^{\mathrm{TM}} \mathrm{S}$ Safety knife (Alcon Laboratories, Inc.) provided by the sponsor. After creating an anterior continuous curvilinear capsulorhexis, phacoemulsification was performed using the Centurion ${ }^{\circledR}$ Active $0.9 \mathrm{~mm}$ MicroSmooth phacoemulsification tip (Alcon Laboratories, Inc.) provided by the sponsor.

Immediately before IOL implantation, each delivery device was prepared according to the manufacturer's instructions. For system U, system S, and the manual system, Viscoat OVD was injected into the delivery device. For system T, Healon EndoCoat ${ }^{\circledR}$ OVD (Abbott Medical Optics Inc) was injected into the delivery device.

Subjects were required to attend a total of three visits over a period of up to 31 days: a screening visit (Visit 0 ), a surgery visit (Visit 00 ), and a Day 1 postoperative follow-up visit (Visit 1).

\section{Effectiveness end points}

The primary effectiveness end point was the corneal incision size after IOL implantation, measured on the surgery day, with preloaded system $U$ as compared to preloaded system $T$ and preloaded system S. The secondary effectiveness end point was the corneal incision size after IOL implantation as compared to the manual delivery system.

Exploratory end points included mean enlargement of the corneal incision size, rate of trapped trailing haptic, rate of IOL adherence to the plunger tip, rate of nozzle tip splitting, and mean SIA at Day 1 postoperative visit. To measure astigmatism, keratometry was performed according to the investigator's standard of care. The same device must have been used throughout the study for all assessment. Curvature and axis for flat (K1) and steep (K2) meridians were recorded.

Safety end points included mean intraocular pressure (IOP), frequency of slit lamp findings, frequency of adverse events (AEs), and frequency of device deficiencies.

\section{Data collection}

\section{Corneal incision size measurements}

Corneal incision size was measured on the day of surgery for each of the delivery systems tested. The method for measuring corneal incision size and enlargement has been previously described. ${ }^{9}$ Three separate incision size measurements were collected during each surgical procedure: initial incision size (measured directly after the clear corneal incision is made), pre-IOL implantation/postphacoemulsification incision size (measured directly after the completion of phacoemulsification), and post-IOL implantation incision size (measured directly after IOL implantation). Incisions were measured using an incision gauge (Capsulorhexis Incision Gauge Set, Product AE-1582T; ASICO, LLC, Westmont, IL, USA) that was $0.1 \mathrm{~mm}$ smaller than the size of the incision made.

\section{Enlargement of corneal incision}

Enlargement of the corneal incision size was calculated as the post-IOL implantation size measured directly after IOL implantation minus the pre-IOL implantation incision size measured directly after the completion of phacoemulsification.

\section{Trapped trailing haptic}

The incidences of trapped trailing haptic during delivery into the capsular bag were assessed visually by the surgeon and scored based on whether a second instrument was required to successfully complete IOL delivery.

\section{Intraocular lens adherence to delivery system plunger}

The rate of IOL adherence to the delivery system plunger tip was assessed by the surgeon immediately after the IOL exited the cartridge for all test articles. The IOL adherence to the delivery system plunger tip occurred if the IOL did not freely release immediately from the plunger tip without additional manipulation or vigorous movement of the plunger itself. 


\section{Splitting of the cartridge tip}

Incidences of nozzle tip splitting were evaluated visually by the surgeon immediately post-IOL implantation by examining them under the surgical microscope.

\section{Adverse events}

An AE was defined as any untoward medical occurrence, unintended disease or injury, or untoward clinical signs (including abnormal laboratory findings) in subjects, users, or other persons, whether or not related to the medical device. An adverse device effect was defined as an AE related to the use of a test article or control article (including AEs resulting from insufficient or inadequate instructions for use, deployment, implantation, installation, or operation; any malfunction; and use error or intentional misuse of the test article or control article). All AEs were coded using the Medical Dictionary for Regulatory Activities (MedDRA, version 19.0). The AEs were analyzed by eyes (ocular) or by subjects (nonocular).

\section{Slit lamp examination}

The conjunctiva, cornea, lens, and iris/anterior chamber were assessed by slit lamp biomicroscopy at the preoperative and postoperative examinations. These examinations were performed before instillation of eye drops.

\section{Tonometry}

IOP was measured with a tonometer at the preoperative and Day 1 postoperative examinations, with each site using the same tonometer device throughout the study for all assessments and all subjects.

\section{Data analysis}

Corneal incision enlargement was calculated as the post-IOL implantation incision size minus the pre-IOL implantation incision size. The frequency of occurrence of trapped trailing haptic, IOL adherence to the plunger tip, nozzle tip splitting, and mean SIA were calculated for each treatment group. Statistical analyses were performed to determine whether there were significant differences between any of the observations for the treatment groups using two-sample $t$-tests. The primary and secondary effectiveness end points were evaluated using a two-sample $t$-test at one-sided alpha of 0.025 , with family-wise type I error controlled at 0.05 .

\section{Sample size justification}

Based on the results of an ex vivo preclinical study in porcine eyes (SD in corneal incision size after IOL implantation ranging from 0.03 to $0.06 \mathrm{~mm}$ ), the planned SD for corneal incision size after IOL implantation in this study was $0.1 \mathrm{~mm} .{ }^{9}$ Assuming 23 subjects per group, there is $\sim 90 \%$ power to demonstrate a difference of $0.1 \mathrm{~mm}$ between any two groups at one-sided alpha of 0.025 . Dropout was expected to be low, and a total of 100 subjects ( 25 per group) were, therefore, planned to achieve the target of 23 subjects per group.

\section{Results}

A total of 109 subjects participated in the study. Subject demographics and baseline characteristics were similar between treatment groups (Table 1). The first primary effectiveness end point was to evaluate the mean corneal incision size after cataract surgery using preloaded system U compared to preloaded system $\mathrm{T}$ and preloaded system $\mathrm{S}$. As shown in Figure $2 \mathrm{~A}$, preloaded system $U$ presented with a significantly smaller corneal incision size of $2.35 \pm 0.019 \mathrm{~mm}$ (mean $\pm \mathrm{SD}$ ) compared to preloaded system $\mathrm{T}$ and preloaded system $\mathrm{S}$ with incision sizes of $2.47 \pm 0.016$ and $2.54 \pm 0.019 \mathrm{~mm}$, respectively $(P<0.001)$. The secondary effectiveness end point was to compare the mean corneal incision size after cataract surgery

Table I Study population demographics and baseline characteristics

\begin{tabular}{|c|c|c|c|c|}
\hline & $\begin{array}{l}\text { Preloaded system } \mathrm{U}, \\
\mathrm{N}=19\end{array}$ & $\begin{array}{l}\text { Preloaded system } \mathrm{T}, \\
\mathrm{N}=26\end{array}$ & $\begin{array}{l}\text { Preloaded system } \mathrm{S}, \\
\mathrm{N}=26\end{array}$ & $\begin{array}{l}\text { Manual delivery system } \\
\mathbf{N}=\mathbf{2 8}\end{array}$ \\
\hline \multicolumn{5}{|l|}{ Age (years) } \\
\hline Mean (SD) & $71.4(8.7)$ & $70.7(8.31)$ & $73.0(7.27)$ & $72.5(7.1)$ \\
\hline \multicolumn{5}{|l|}{ Sex } \\
\hline Female, n (\%) & $14(73.7)$ & $13(50.0)$ & $14(53.8)$ & $17(60.7)$ \\
\hline \multicolumn{5}{|l|}{ Race } \\
\hline White, n (\%) & $19(100.0)$ & $26(100.0)$ & $26(100.0)$ & $28(100.0)$ \\
\hline \multicolumn{5}{|c|}{ Preoperative UCDVA (logMAR) } \\
\hline Mean (SD) & $0.58(0.4)$ & $0.53(0.3)$ & $0.60(0.4)$ & $0.66(0.3)$ \\
\hline \multicolumn{5}{|c|}{ Preoperative absolute keratometry } \\
\hline \multicolumn{5}{|c|}{ (KI-K2) (diopters) } \\
\hline Mean (SD) & $0.57(0.2)$ & $0.56(0.3)$ & $0.55(0.2)$ & $0.46(0.3)$ \\
\hline \multicolumn{5}{|c|}{ Preoperative IOP $(\mathrm{mmHg})$} \\
\hline Mean (SD) & $14.7(2.0)$ & $14.9(2.9)$ & I5.3 (2.4) & $15.6(3.1)$ \\
\hline
\end{tabular}

Abbreviations: IOP, intraocular pressure; UCDVA, uncorrected distance visual acuity. 
A

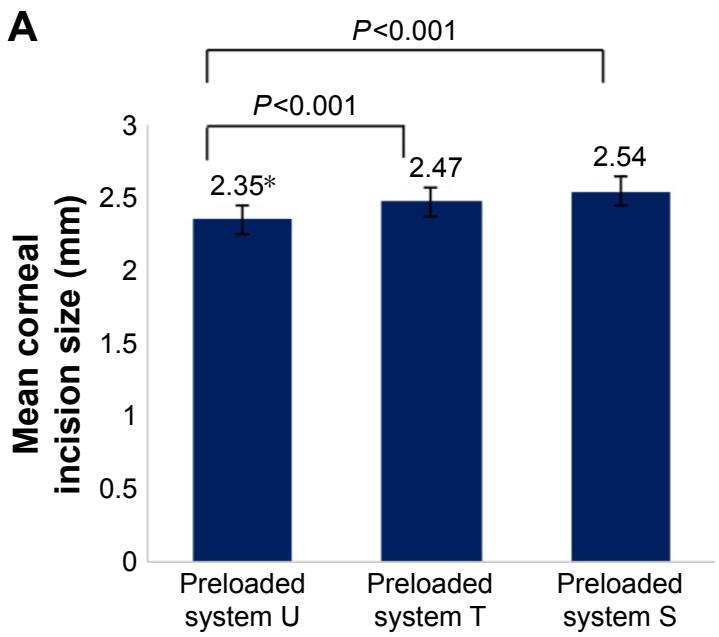

B

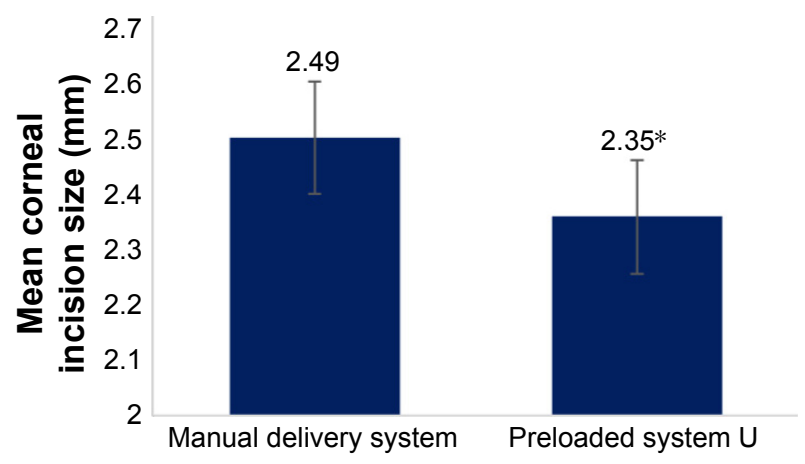

Figure 2 Mean corneal incision size after intraocular lens implantation of preloaded systems or manual delivery system.

Notes: (A) Preloaded system $U$ had the smallest mean corneal incision size among the preloaded devices. Preloaded systems T and S resulted in significantly greater mean corneal incision sizes. (B) Preloaded system $U$ resulted in a significantly smaller mean corneal incision size than the manual delivery system. Data presented as mean \pm standard error; $n=19$ eyes for preloaded system $U, 26$ eyes for preloaded system T, 26 eyes for preloaded system $S$, and 28 eyes for the manual delivery system. *Statistical significance $(P<0.025)$, as determined by a two-sample $t$-test based on superiority hypothesis testing as compared to preloaded system $\mathrm{T}$, system $\mathrm{S}$, or the manual delivery system.

using preloaded system $U$ or the manual delivery system. Preloaded system U demonstrated similarly favorable performance when compared with the manual delivery system, which had a mean corneal incision size of $2.49 \pm 0.011 \mathrm{~mm}$ $(P<0.001$; Figure 2B).

In evaluating the first exploratory end point, enlargement of corneal incision size was calculated by subtracting the pre-IOL implantation size from the post-IOL implantation size. For the three preloaded delivery systems (Figure 3A), the least amount of enlargement of the corneal incision size was observed with preloaded system $\mathrm{U}$ (mean $[\mathrm{SD}]=0.11[0.06] \mathrm{mm}$ ) as compared to preloaded system $\mathrm{T}$ (mean $[\mathrm{SD}]=0.19[0.07] \mathrm{mm}$ ) and preloaded system $\mathrm{S}$ (mean $[\mathrm{SD}]=0.27[0.08] \mathrm{mm}$ ). As presented in Figure 3B, the least amount of enlargement of the corneal incision size was observed with the manual delivery system (mean $[\mathrm{SD}]=0.08[0.07] \mathrm{mm}$ ). Corneal incision size enlargement was not statistically significantly different between system $\mathrm{U}$ and any of the other delivery systems.

The least amount of SIA at Day 1 postoperative was observed with preloaded system U (SIA Centroid $=0.10 \mathrm{D}$ [axis: $83.06^{\circ}$ ]) as compared to preloaded system T (SIA Centroid $=0.20 \mathrm{D}$ [axis: $94.00^{\circ}$ ]), preloaded system $\mathrm{S}$ (SIA Centroid $=0.48 \mathrm{D}$ [axis: $65.16^{\circ}$ ]), and the manual delivery system (SIA Centroid $=0.33 \mathrm{D}$ [axis: $37.84^{\circ}$ ]) (Figure 4A and B).

There were five occurrences of trapped trailing haptic observed in the study, all of which occurred using preloaded
A

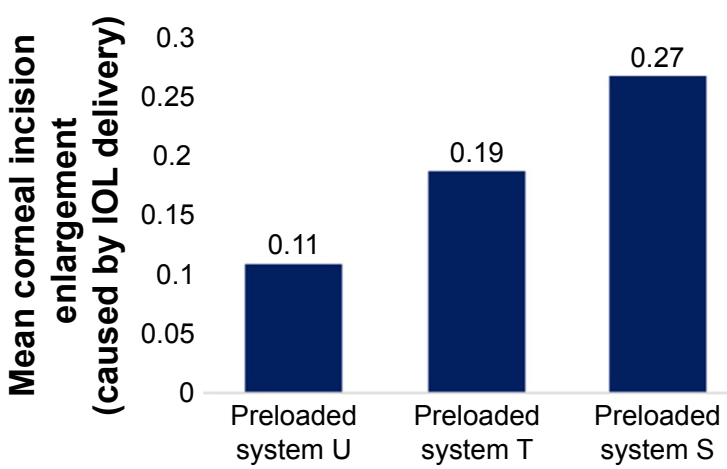

B

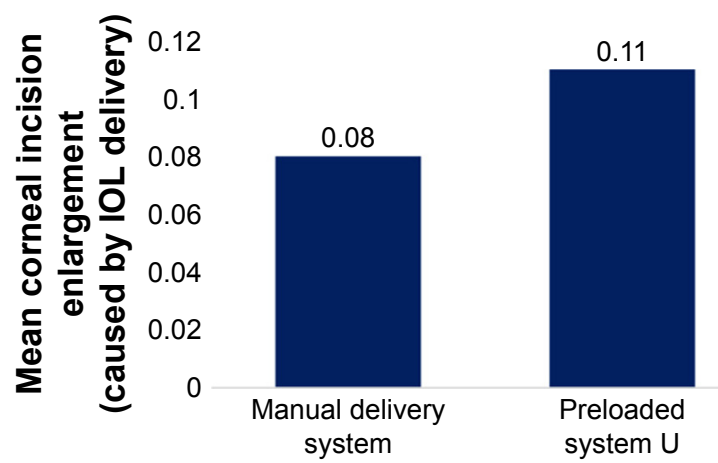

Figure 3 Mean corneal incision size enlargement caused by IOL delivery using preloaded systems or manual delivery system.

Notes: (A) Preloaded system $U$ had the least corneal incision enlargement among the preloaded devices. Incision enlargements following IOL insertion using preloaded system $\mathrm{T}$ and system $\mathrm{S}$ were greater than those of system $U$. (B) The manual delivery system resulted in less corneal incision enlargement than preloaded system $U$ and had the least mean corneal incision enlargement of all the devices tested. Data presented as mean; $n=19$ eyes for preloaded system $U$, 26 eyes for preloaded system T, 26 eyes for preloaded system $\mathrm{S}$, and 28 eyes for the manual delivery system.

Abbreviation: IOL, intraocular lens. 

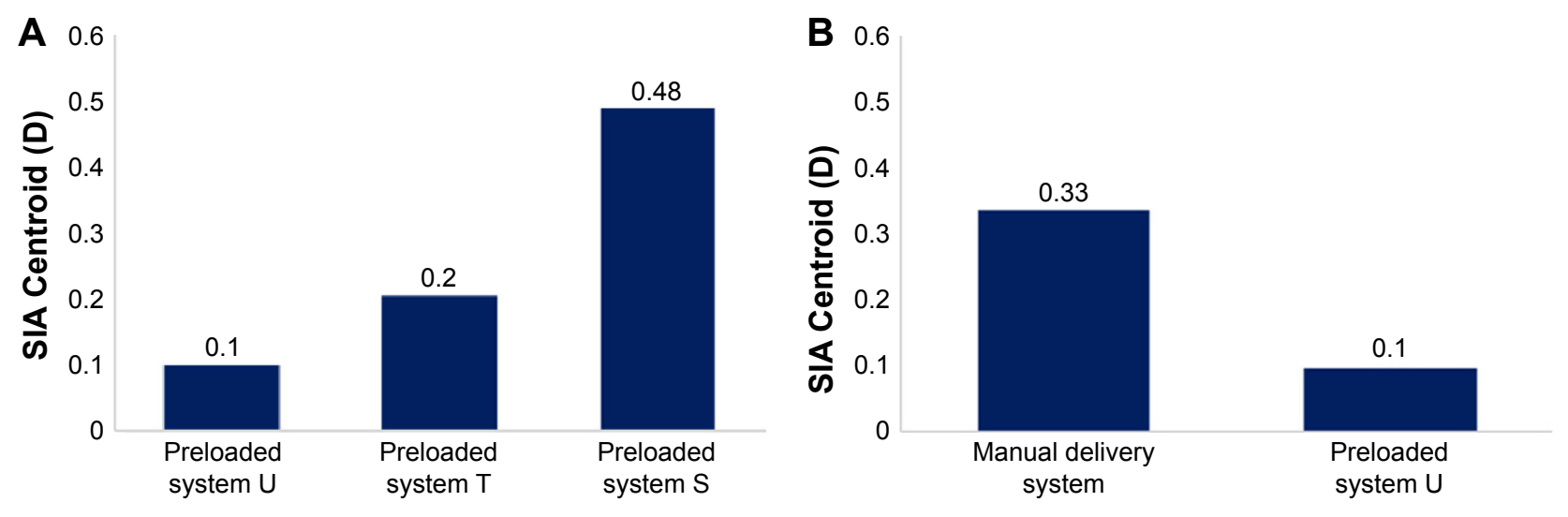

Figure 4 SIA following implantation of preloaded systems or manual delivery system.

Notes: (A) Less SIA was observed in patients following intraocular lens insertion using preloaded system $U$ than that of systems $T$ and $S$. (B) Preloaded system $U$ also resulted in less SIA than the manual delivery system. Data presented as mean; $n=19$ eyes for preloaded system $U, 26$ eyes for preloaded system T, 26 eyes for preloaded system $S$, and 28 eyes for the manual delivery system.

Abbreviations: D, diopters; SIA, surgically induced astigmatism.

system T (19.2\% of system T group, N=26; Table 2). Preloaded system $\mathrm{U}$, preloaded system $\mathrm{S}$, and the manual delivery system presented no cases of trapped trailing haptic. There was one instance of IOL adherence to the plunger tip observed, which occurred using preloaded system S only (3.8\% of system $\mathrm{S}$ group, $\mathrm{N}=26$ ). In addition, there were six instances of nozzle tip splitting observed in the study with the preloaded system $\mathrm{S}$ (23.1\% of system $\mathrm{S}$ group, $\mathrm{N}=26$ ). No instances of IOL adherence to the plunger tip or nozzle tip splitting were observed in any of the other three delivery devices tested.

Two treatment emergent ocular serious adverse events (SAEs) were reported in the study (Table 3). One eye randomized to the preloaded system $\mathrm{T}$ experienced two treatment emergent ocular SAEs, which were mild in severity and resolved. The subject underwent a secondary surgical intervention (surgical procedure repeated) using the phacoemulsification machine to remove a small residual cortical lens fragment (cataract operation complication). The subject did not discontinue the study due to these ocular SAEs. In addition, one treatment emergent ocular AE occurred in a subject randomized to preloaded system $\mathrm{S}$, which resolved. All ocular AEs (serious and nonserious) were assessed as not related to the investigational study device. No nonocular AEs were reported in the study.

\section{Discussion}

Phacoemulsification followed by IOL implantation remains the primary procedural choice for the treatment of cataracts in the developed nations. ${ }^{10-13}$ Recent advances in the design of both IOLs and IOL delivery systems have significantly improved patient outcomes following cataract surgery. ${ }^{14-18}$ The shift from rigid polymethyl methacrylate IOLs to foldable silicone and acrylic lenses has enabled the use of smaller incision sizes, ${ }^{19}$ which help promote faster healing while reducing the risk of astigmatism, inflammation, and postoperative endophthalmitis. ${ }^{11,20-22}$ However, while small incision size offers many benefits, these benefits are negated if the incision is too small to accommodate the IOL or its delivery system, which can result in incision tearing or distortions. ${ }^{11,20-22}$ Thus, there is a need for IOL delivery devices that are capable of insertion via small incisions while maintaining incision integrity.

Numerous studies have demonstrated the importance of smaller incision size in reducing the risk of SIA. ${ }^{23-25} \mathrm{Wang}$ et al found that 2.2- and 2.6-mm incisions resulted in significantly lower SIA than $3.0-\mathrm{mm}$ incisions in patients undergoing microincision and small incision cataract surgery. ${ }^{23}$ Tetikoğlu et al evaluated the effect of incision enlargement on rates of SIA after biaxial phacoemulsification and found

Table 2 Observations of IOL-delivery device interactions and surgically induced astigmatism

\begin{tabular}{lllll}
\hline & $\begin{array}{l}\text { Preloaded system } \mathbf{~}, \\
\mathbf{N}=\mathbf{1 9}\end{array}$ & $\begin{array}{l}\text { Preloaded system T, } \\
\mathbf{N}=\mathbf{2 6}\end{array}$ & $\begin{array}{l}\text { Preloaded system S, } \\
\mathbf{N}=\mathbf{2 6}\end{array}$ & $\begin{array}{l}\text { Manual delivery system, } \\
\mathbf{N}=\mathbf{2 8}\end{array}$ \\
\hline Trapped trailing haptic, $\mathrm{n}(\%)$ & $0(0.0)$ & $5(19.2)$ & $0(0.0)$ & $0(0.0)$ \\
Plunger tip adherence, $\mathrm{n}(\%)$ & $0(0.0)$ & $0(0.0)$ & $\mathrm{I}(3.8)$ & $0(0.0)$ \\
Nozzle tip splitting, $\mathrm{n}(\%)$ & $0(0.0)$ & $0(0.0)$ & $6(23.1)$ & $0(0.0)$ \\
Overall surgically induced & $0.10(83.06)$ & $0.20(94.00)$ & $0.48(65.16)$ & $0.33(37.84)$ \\
astigmatism, diopters (axis) & & & & \\
\hline
\end{tabular}


Table 3 Treatment emergent ocular adverse events (serious and nonserious)

\begin{tabular}{lllll}
\hline & $\begin{array}{l}\text { Preloaded system } \mathbf{~}, \\
\text { N=19 }\end{array}$ & $\begin{array}{l}\text { Preloaded system T, } \\
\text { N=26 }\end{array}$ & $\begin{array}{l}\text { Preloaded system S, } \\
\text { N=26 }\end{array}$ & $\begin{array}{l}\text { Manual delivery system, } \\
\text { N=28 }\end{array}$ \\
\hline Cataract operation complication, n (\%) & $0(0.0)$ & $\mathrm{I}(3.8)$ & $0(0.0)$ & $0(0.0)$ \\
Corneal edema, $\mathrm{n}(\%)$ & $0(0.0)$ & $0(0.0)$ & $\mathrm{I}(3.8)$ & $0(0.0)$ \\
Surgical procedure repeated, n (\%) & $0(0.0)$ & $\mathrm{I}(3.8)$ & $0(0.0)$ & $0(0.0)$ \\
\hline
\end{tabular}

that there is a significant increase in SIA as incision size increased from 2.0 to $2.8 \mathrm{~mm}^{7}$

However, some studies have shown that a more complex relationship may exist between corneal incision size and SIA. Wei et al found that mean SIA in patients with a $3.5-\mathrm{mm}$ incision was significantly greater than that in patients with a 2.5-mm incision, but the results were only significant in the first 6 weeks after the operation. ${ }^{26}$ At 12 weeks, the correlation between incision size and SIA diminished and was no longer deemed significant. In addition, while smaller incision sizes tend to correlate with lower SIA, care must also be taken to ensure that the incision is large enough to minimize damage to the surrounding corneal tissue during IOL insertion. For example, Moon et al found that the optimal incision size for reducing postoperative SIA was $3.0-\mathrm{mm}$ compared to 2.5- or 3.5-mm incisions. ${ }^{25}$ It is difficult to understand how a $2.5-\mathrm{mm}$ incision could be worse than a $3.0-\mathrm{mm}$ incision, but the finding might be explained by considering how well the architecture of the incision is preserved. In this case, the smaller incision might have yielded better results if different tools (preloaded delivery systems, IOLs) had been used that were more successful in maintaining the integrity and architecture of the original incision. Collectively, these studies highlight the need for instruments that are capable of striking a balance between small incision size and preservation of incision architecture.

This study validates previous preclinical results, in that preloaded system $U$ provided the smallest final corneal incision size among all the tested preloaded devices. ${ }^{9}$ Among the preloaded devices, used as manufacturers recommended through 2.2-mm incisions, preloaded system $U$ also performed best in terms of incision enlargement. ${ }^{9}$ Preloaded system $U$ is the system that widens the incision less and results in the least amount of SIA at the Day 1 postoperative visit. The results of our study concur with those of Wang et al and suggest that the delivery device with the smallest overall incision size also correlates with the lowest levels of postoperative astigmatism. ${ }^{9}$

The manual system allowed implantations with minimal widening of the incision $(0.08 \mathrm{~mm})$. However, it should be mentioned that the initial incision recommended by the manufacturer for the manual system was $2.4 \mathrm{~mm}$ but the final incision was wider $(2.49 \mathrm{~mm})$ than that observed with the system $U(2.35 \mathrm{~mm})$.

Of the four delivery systems tested, preloaded system U is unique, in that it possesses a depth guard to help control insertion depth, which serves to minimize incision enlargement and preserve the integrity of the incision. Previous IOL injector systems lacking this feature were prone to problems such as insertional errors and nozzle tip splitting, which can cause damage to the IOL. ${ }^{19}$ The depth guard may also serve to augment the mechanical strength of the cartridge tip, providing further protection against nozzle splitting as the IOL passes through the nozzle during delivery. The depth guard may help to ensure procedural reproducibility by minimizing variation in insertion technique, allowing for more consistent and effective application.

One limitation of this study is that the measurements for astigmatism were taken 1 day after surgery was performed. While the greatest degree of postoperative SIA is expected to occur and then stabilize within the first couple of weeks after surgery, changes in the cornea can affect SIA for up to a year and future studies will be designed to collect SIA data at additional postoperative timepoints, including 1 week, 1 month, and 3 months. ${ }^{27-29}$ Another limitation is that the study was not powered to evaluate the potential for statistically significant differences in postoperative SIA between groups.

While this study was able to characterize the effect of different IOL delivery devices on the corneal incision size, future studies should be conducted to assess the potential impact of these devices on the morphology of the corneal incision (eg, epithelial/endothelial gaping, Descemet membrane detachment, and corneal thickness).

\section{Conclusion}

Preloaded system U showed the smallest final corneal incision size compared to the other three delivery systems tested. Preloaded system U demonstrated no instances of trapped trailing haptic or nozzle tip splitting and exhibited the smallest mean corneal incision enlargement among the preloaded devices. Preloaded system U may provide a clinical improvement in IOL delivery for patients undergoing cataract surgery. 


\section{Data sharing statement}

The study and analytic methods used to support the findings of this study may be released to other researchers upon application to the sponsor, who can be contacted at www. alcon.com/about-us/contact/general-inquiry.

\section{Acknowledgments}

This study was supported by Alcon. Editorial support was provided by Zachary Harrelson, $\mathrm{PhD}$, on behalf of Fishawack Communications, and was contracted and funded by Alcon Laboratories, Inc.

\section{Author contributions}

All authors contributed toward data analysis, drafting, and critically revising the manuscript, gave final approval of the version to be published, and agreed to be accountable for all aspects of the work.

\section{Disclosure}

Lixin Wang, $\mathrm{MD}, \mathrm{PhD}$, is a full-time employee of Novartis Pharmaceuticals Corporation. Aldo A Martinez, $\mathrm{PhD}$, is a full-time employee of Alcon Laboratories, Inc. Javier Mendicute, $\mathrm{MD}, \mathrm{PhD}$, is a consultant for Alcon Laboratories, Inc., and received research support from Alcon Laboratories, Inc., AcuFocus, Inc., MEDICEM, Novagali Pharma S.A., and Carl Zeiss Meditec, Inc. Thierry Amzallag, MD, has received personal fees from Alcon Laboratories, Cutting Edge, and Théa, and is a clinical trial investigator for Zeiss. The authors report no other conflicts of interest in this work.

\section{References}

1. Kohnen T, Baumeister M, Kook D, Klaproth O, Ohrloff C. Cataract surgery with implantation of an artificial lens. Dtsch Arztebl Int. 2009; 106(43):695-702.

2. Endophthalmitis Study Group, European Society of Cataract and Refractive Surgeons. Prophylaxis of postoperative endophthalmitis following cataract surgery: results of the ESCRS multicenter study and identification of risk factors. J Cataract Refract Surg. 2007;33(6):978-988.

3. Alió JL, Schimchak P, Montés-Micó R, Galal A. Retinal image quality after microincision intraocular lens implantation. $J$ Cataract Refract Surg. 2005;31(8):1557-1560.

4. Kahraman G, Amon M, Franz C, Prinz A, Abela-Formanek C. Intraindividual comparison of surgical trauma after bimanual microincision and conventional small-incision coaxial phacoemulsification. J Cataract Refract Surg. 2007;33(4):618-622.

5. Shimizu K, Kobayashi K, Takayama S, Zhaobin G. Preloaded injector for intraocular lens implantation without the use of ophthalmic viscosurgical devices. J Cataract Refract Surg. 2008;34(7):1157-1160.

6. Allen D, Habib M, Steel D. Final incision size after implantation of a hydrophobic acrylic aspheric intraocular lens: New motorized injector versus standard manual injector. J Cataract Refract Surg. 2012;38(2): 249-255.

7. Tetikoğlu M, Yeter C, Helvacioğlu F, Aktas S, Sağdik H, Ozcura F. Effect of corneal incision enlargement on surgically induced astigmatism in biaxial microincision cataract surgery. Turk J Ophthalmol. 2016; 46(3):99-103.
8. Jones JJ, Chu J, Graham J, Zaluski S, Rocha G. The impact of a preloaded intraocular lens delivery system on operating room efficiency in routine cataract surgery. Clin Ophthalmol. 2016;10:1123-1129.

9. Wang L, Wolfe P, Chernosky A, Paliwal S, Tjia K, Lane S. In vitro delivery performance assessment of a new preloaded intraocular lens delivery system. J Cataract Refract Surg. 2016;42(12):1814-1820.

10. Hennig A, Puri LR, Sharma H, Evans JR, Yorston D. Foldable vs rigid lenses after phacoemulsification for cataract surgery: a randomized controlled trial. Eye (Lond). 2014;28(5):567-575.

11. Khokhar S, Sharma R, Patil B, Aron N, Gupta S. Comparison of new motorized injector vs manual injector for implantation of foldable intraocular lenses on wound integrity: an ASOCT study. Eye (Lond). 2014;28(10):1174-1178.

12. Leaming DV. Practice styles and preferences of ASCRS memberssurvey 2001. J Cataract Refract Surg. 2002;28(9):1681-1688.

13. Arthur E, Sadik AA, Kumah DB, et al. Postoperative corneal and surgically induced astigmatism following superior approach manual small incision cataract surgery in patients with preoperative against-the-rule astigmatism. J Ophthalmol. 2016;2016:9489036.

14. Hayashi K, Hayashi H, Nakao F, Hayashi F. The correlation between incision size and corneal shape changes in sutureless cataract surgery. Ophthalmology. 1995;102(4):550-556.

15. Jiang Y, Le Q, Yang J, Lu Y. Changes in corneal astigmatism and high order aberrations after clear corneal tunnel phacoemulsification guided by corneal topography. J Refract Surg. 2006;22(9 Suppl): S1083-S1088.

16. Kohnen S, Neuber R, Kohnen T. Effect of temporal and nasal unsutured limbal tunnel incisions on induced astigmatism after phacoemulsification. J Cataract Refract Surg. 2002;28(5):821-825.

17. Kohnen T, Dick B, Jacobi KW. Comparison of the induced astigmatism after temporal clear corneal tunnel incisions of different sizes. J Cataract Refract Surg. 1995;21(4):417-424.

18. Ventura BV, Wang L, Weikert MP, Robinson SB, Koch DD. Surgical management of astigmatism with toric intraocular lenses. Arq Bras Oftalmol. 2014;77(2):125-131.

19. Harsum S, Mann S, Clatworthy I, Lewin J, Little B. An investigation of intraocular lens damage and foreign bodies using an injectable hydrophilic acrylic lens implant. Eye. 2010;24(1):152-157.

20. Masket S, Wang L, Belani S. Induced astigmatism with 2.2- and 3.0-mm coaxial phacoemulsification incisions. J Refract Surg. 2009; 25(1):21-24.

21. Hayashi K, Yoshida M, Hayashi H. Postoperative corneal shape changes: microincision versus small-incision coaxial cataract surgery. J Cataract Refract Surg. 2009;35(2):233-239.

22. Elkady B, Pinero D, Alio JL. Corneal incision quality: microincision cataract surgery versus microcoaxial phacoemulsification. $J$ Cataract Refract Surg. 2009;35(3):466-474.

23. Wang J, Zhang EK, Fan WY, Ma JX, Zhao PF. The effect of microincision and small-incision coaxial phaco-emulsification on corneal astigmatism. Clin Exp Ophthalmol. 2009;37(7):664-669.

24. Yang J, Wang X, Zhang H, Pang Y, Wei RH. Clinical evaluation of surgery-induced astigmatism in cataract surgery using $2.2 \mathrm{~mm}$ or $1.8 \mathrm{~mm}$ clear corneal micro-incisions. Int J Ophthalmol. 2017;10(1):68-71.

25. Moon SC, Mohamed T, Fine IH. Comparison of surgically induced astigmatisms after clear corneal incisions of different sizes. Korean $J$ Ophthalmol. 2007;21(1):1-5.

26. Wei YH, Chen WL, Su PY, Shen EP, Hu FR. The influence of corneal wound size on surgically induced corneal astigmatism after phacoemulsification. J Formos Med Assoc. 2012;111(5):284-289.

27. Masket S, Tennen DG. Astigmatic stabilization of $3.0 \mathrm{~mm}$ temporal clear corneal cataract incisions. J Cataract Refract Surg. 1996;22(10): 1451-1455.

28. Pfleger T, Skorpic C, Menapace R, Scholz U, Weghaupt H, Zehetmayer M. Long-term course of induced astigmatism after clear corneal incision cataract surgery. J Cataract Refract Surg. 1996;22(1):72-77.

29. Ermiş SS, Inan UU, Oztürk F. Surgically induced astigmatism after superotemporal and superonasal clear corneal incisions in phacoemulsification. J Cataract Refract Surg. 2004;30(6):1316-1319. 
Clinical Ophthalmology

\section{Publish your work in this journal}

Clinical Ophthalmology is an international, peer-reviewed journal covering all subspecialties within ophthalmology. Key topics include: Optometry; Visual science; Pharmacology and drug therapy in eye diseases; Basic Sciences; Primary and Secondary eye care; Patien Safety and Quality of Care Improvements. This journal is indexed on

PubMed Central and CAS, and is the official journal of The Society of Clinical Ophthalmology (SCO). The manuscript management system is completely online and includes a very quick and fair peer-review system, which is all easy to use. Visit http://www.dovepress.com/ testimonials.php to read real quotes from published authors. 